EDITORIAL

\title{
El síndrome del pie diabético: una entidad de etiología multifactorial que debe ser prevenida
}

\author{
Yulino Castillo-Núñez y Carlos Aguilar-Salinas²
}

${ }^{1}$ Jefe del Departamento de Endocrinología, Hospital Dr. Salvador B. Gautier, Santo Domingo, República Dominicana, Coeditor y codirector de la Revista de la Asociación Latinoamericana de Diabetes (ALAD); ${ }^{2}$ Jefe de la Unidad de Investigación de Enfermedades Metabólicas, Instituto Nacional de Ciencias Médicas y Nutrición Salvador Zubirán, Ciudad de México, Máxico; Coeditor y codirector de la Revista de la Asociación Latinoamericana de Diabetes (ALAD)

Se denomina pie diabético a la condición en la que la neuropatía, la isquemia y la infección provocan destrucción tisular en uno o ambos pies de pacientes con diabetes mellitus, resultando en morbilidad, discapacidad y posible mortalidad prematura.

La neuropatía conlleva:

- Pérdida de la sensación protectora por neuropatía periférica sensorial, lo que se traduce en la no percepción de trauma repetido, sea este mecánico, térmico o químico.

- Atrofia de los músculos intrínsecos del pie debido a neuropatía periférica motora. Esto provoca un desequilibrio de los músculos extensores y flexores del pie, con la aparición de pie deformado por dedos en garra o dedos en martillo, lo que da lugar a nuevos puntos de presión que favorecen la ulceración.

- Autosimpatectomía por neuropatía autonómica, que puede producir aumento del flujo sanguíneo local, incremento de la resorción ósea, colapso articular y pie deformado (pie de Charcot), lo que facilita la creación de nuevos puntos de presión, favoreciendo el desarrollo de úlceras.

- Piel seca y agrietada, que provoca fisuras cutáneas y predisposición a infección.

La isquemia por insuficiencia arterial periférica disminuye el aporte de oxígeno, antibióticos y nutrientes a los tejidos del pie, lo que predispone a retraso de la cicatrización de las heridas y al desarrollo de infección. Además, la embolia de colesterol y la llamada arterioesclerosis obliterans pueden ser causa de gangrena mayor.

La hiperglucemia disminuye la fagocitosis, la adherencia, la quimiotaxis y la actividad oxidativa y bactericida de los neutrófilos, lo que aumenta la susceptibilidad a la infección en el contexto de una inmunopatía diabética. Esta tríada patogénica de neuropatía, angiopatía e inmunopatía, en presencia de trauma, condiciona el desarrollo de ulceración del pie, con la subsiguiente invasión bacteriana e infección ${ }^{1,2}$. 
Así pues, podríamos hablar de las «5 A» en el desarrollo del pie diabético:

- Anestesia (pérdida de la sensación protectora debido a neuropatía periférica sensorial).

- Atrofia de los músculos intrínsecos del pie debido a neuropatía periférica motora.

- Autosimpatectomía por neuropatía autonómica.

- Anhidrosis por neuropatía autonómica.

- Angiopatía (enfermedad arterial periférica).

Las úlceras del pie en pacientes diabéticos tienen una prevalencia del 3-8\% y constituyen una de las causas evitables de hospitalización en este grupo de pacientes. Alrededor de un $15-25 \%$ de los pacientes diabéticos desarrollará úlceras en el pie en el curso de su enfermedad ${ }^{2}$. El síndrome del pie diabético es la causa del 70-90\% de las amputaciones en diabéticos. En tal sentido, la diabetes mellitus es la causa más frecuente de amputación no traumática de miembros inferiores a nivel mundial, estimándose que el 40-60\% de todas las amputaciones están relacionadas con esta condición.

En el presente número de la Revista de la Asociación Latinoamericana de Diabetes (ALAD) se presenta la posición de un panel multidisciplinario de expertos colombianos sobre la atención inicial del pie diabético $^{3}$. En este documento se discuten los resultados de una búsqueda amplia de la literatura médica sobre el pie diabético, seleccionándose guías basadas en la evidencia, revisiones sistemáticas, ensayos clínicos aleatorizados en fase III y estudios observacionales. El grupo plantea una realidad que suele ser común en muchos países de Latinoamérica:
- Los sistemas de salud de la región están mal preparados para atender las necesidades básicas de los pacientes con pie diabético.

- El tiempo de consulta que se dedica a los pacientes con pie diabético suele ser muy limitado, y menor el que se dedica a la prevención de las lesiones.

- Muchas veces los profesionales de la salud que asisten a los pacientes con pie diabético no cuentan con la formación y las destrezas clínicas adecuadas para ofertarles una atención de calidad.

- Las medidas de prevención del pie diabético resultan insuficientes, toda vez que en un estudio se encontró que más del $75 \%$ de los pacientes con diabetes mellitus no había recibido un examen físico de sus pies durante el último año.

- Los pacientes con diabetes mellitus no suelen recibir una educación adecuada sobre el cuidado de sus pies y las medidas que deben tomar para prevenir la aparición de úlceras en los miembros inferiores.

Las lesiones en los pies del paciente con diabetes constituyen una de las complicaciones crónicas de la enfermedad que ha tenido una gran reducción en su incidencia en los países desarrollados. Acciones puntuales como los programas de desarrollo de competencias específicas en personal no médico, acceso a materiales ortopédicos que permitan la descarga de la presión en puntos de soporte anormales y la referencia oportuna permiten disminuir en un periodo corto de tiempo el número de personas que sufren discapacidad o amputaciones. Las guías de práctica clínica adaptadas al entorno donde serán aplicadas, con algoritmos de fácil implementación, son elementos 
clave de dichos programas. Sin embargo, se requiere de su aceptación y aplicación por los usuarios. Es urgente que en nuestra región latinoamericana los sistemas de salud, las diversas sociedades científicas que aglutinan médicos que asisten a personas con diabetes mellitus y las asociaciones de pacientes afectados por esta condición asuman programas y políticas que fomenten la educación en el paciente y la formación de especialistas en la prevención, diagnóstico y tratamiento del pie diabético en el primer nivel de atención. El documento de Luján, et al. publicado en este número de la revista 3 es una llamada para terminar con la inercia de los profesionales de la salud y los tomadores de decisiones hacia el pie diabético.

Los doctores Yulino Castillo Núñez y Carlos AguilarSalinas declaran no tener conflictos de interés en la redacción del presente editorial.

\section{BIBLIOGRAFÍA}

1. Mishra SC, Chhatbar KC, Kashikar A, Mehndiratta A. Diabetic foot. BMJ. 2017;359:i5064.

2. Armstrong DG, Boulton AJM, Bus SA. Diabetic foot ulcers and their recurrence. N Engl J Med. 2017;376(24):2367-75.

3. Luján D, Orduz A, González AL, et al. Panel de expertos sobre la atención inicial del pie diabético. Rev ALAD. 2018;8:19-31. 